\title{
Effects of temporal variations between contingent and probabilistic noncontingent reinforcement
}

\author{
VICTOR A. BENASSI \\ California State University, Long Beach, California 90840 \\ and \\ JEFFREY WEIL and ROBERT N. LANSON \\ Queens College of the City University of New York, New York, New York 11367
}

\begin{abstract}
Pigeons were exposed to a fixed-interval schedule of contingent reinforcement $(t=120 \mathrm{sec})$. Subsequently, noncontingent reinforcement was added to the baseline schedule. Subjects received contingent reinforcement for the first keypeck in each interval and noncontingent reinforcement at a specified temporal locus in the interval. Subjects were exposed to different loci of noncontingent reinforcement $(20,60$, and $100 \mathrm{sec})$ during different phases of the study, and the probability of noncontingent reinforcement was systematically varied at each locus across sessions. Several subjects showed decreases in response rates as the probability of noncontingent reinforcement was increased. Other subjects either did not show systematic changes in rate or showed increases in rate with increases in noncontingent reinforcement probability. Changes in temporal separation between contingent and noncontingent reinforcement did not produce systematic differences in the relation between response rate and noncontingent reinforcement probability. Postreinforcement pauses after contingent and noncontingent reinforcement varied consistently with temporal location, but not with probability, of noncontingent reinforcement.
\end{abstract}

Rachlin and Baum (1972) examined the effects of two sources of reinforcement on a single response. Pigeons were trained to keypeck for contingent reinforcement $\left(\mathrm{S}_{\mathrm{C}}^{\mathrm{R}}\right)$ according to a variable-internal schedule. Concurrently, noncontingent reinforcement $\left(S_{N C}^{R}\right)$ was delivered independent of any particular response at the end of variable time intervals. With the frequency of the two schedules held constant, the magnitudes of $S_{C}^{R}$ and $\mathrm{S}_{\mathrm{NC}}^{\mathrm{R}}$ were varied; subsequently, with magnitudes kept unchanged the frequencies of the schedules were varied. Less keypecking occurred as the magnitude or frequency of $\mathrm{S}_{\mathrm{N}}^{\mathbf{R}}$ was increased relative to the magnitude or frequency of $S_{C}^{R}$. In related studies, Cole (1973) and Lattal (1974) obtained similar results.

In the present study, with $S_{C}^{R}-S_{N}^{R}$ temporal relations controlled, the frequency of $\mathrm{S}_{\mathrm{N}}^{\mathrm{R}}$ was varied. The previously cited experiments were not concerned with controlling the temporal relations between $S_{\mathbf{C}}^{R}$ and $S_{N}^{R}$. In the three studies, the $S_{C}^{R}$ and $S_{N}^{R}$ schedules were either both variable interval or random interval, which resulted in irregular temporal relations between reinforcers. In the present study, the temporal separations between $S_{C}^{R}$ and $S_{N}^{R}$ were more regular. This manipulation was ac-

Requests for reprints should be sent to V.A. Benassi, Psychology Department, California State University, Long Beach, California, 90840. The assistance of Barbara Benassi is acknowledged. This paper is sponsored by Ralph B. Hupka, who takes full editorial responsibility for its contents. complished by the use of a fixed-interval baseline maintained by $S_{C}^{R}$ to which $S_{N}^{R}$ c was added at a particular temporal locus in the interval. Pigeons received $S_{\mathbf{C}}^{R}$ for the first response in an interval and $S_{\mathbf{N}}^{R}$ at the specified point in the interval. The birds were exposed to three loci of $S_{N C}^{R}$, and the probability ( $p$ ) of $S_{N C}^{R}$ was varied at each locus across sessions. The exact temporal separations between $S_{C}^{R}$ and $S_{N C}^{R}$ were dependent on when in the fixed interval a pigeon made its first keypeck.

\section{METHOD}

\section{Subjects}

Six White Carneaux pigeons were maintained at $80 \%$ of their freefeeding body weights. All birds had been previously used in a study of concurrent contingent and noncontingent reinforcement.

\section{Apparatus}

Pecks closing the switch behind the center response key (continuously illuminated by amber light) of a three-key Lehigh Valley Electronics pigeon chamber served as the response. All reinforcements consisted of 3-sec access to mixed grain. A houselight provided illumination throughout experimental sessions. All programming functions were controlled by solid state logic circuitry. Data were recorded on Sodeco counters.

\section{Procedure}

Pigeons were exposed to a baseline schedule of reinforcement in which the first response in a repeating 120-sec time period was contingently and immediately reinforced. Subsequently, noncon- 
Table 1

The Order of Presentation of the Loci and Probabilities of Noncontingent Reinforcement

\begin{tabular}{|c|c|c|c|c|c|c|c|c|c|c|}
\hline \multirow{2}{*}{$\begin{array}{l}\text { Condi- } \\
\text { tiont }\end{array}$} & 213 an & \multirow{2}{*}{$\frac{455}{p^{* *}}$} & \multicolumn{2}{|c|}{100} & \multicolumn{2}{|c|}{$\begin{array}{c}\text { Subject Number } \\
218 \\
\end{array}$} & \multicolumn{2}{|c|}{404} & \multicolumn{2}{|c|}{50} \\
\hline & $\mathrm{L}^{*}(\sec )$ & & L (sec) & $\mathrm{p}$ & $\mathrm{L}(\mathrm{sec})$ & $\mathrm{p}$ & L (sec) & $\mathrm{p}$ & $\mathrm{L}(\mathrm{sec})$ & $\mathrm{p}$ \\
\hline \multicolumn{11}{|l|}{1} \\
\hline 2 & 100 & 1 & 100 & 1 & 100 & 1 & 60 & .25 & 20 & .50 \\
\hline 3 & 100 & .50 & 100 & .50 & 100 & .25 & 60 & 1 & 20 & .25 \\
\hline 4 & 100 & .25 & 100 & .25 & 100 & .50 & 60 & .50 & 20 & 1 \\
\hline \multicolumn{11}{|l|}{5} \\
\hline 6 & 60 & 1 & & & & & & & & \\
\hline 7 & 60 & .50 & & & & & & & & \\
\hline 8 & 60 & .25 & & & & & & & & \\
\hline \multicolumn{11}{|l|}{9} \\
\hline 10 & 20 & 1 & & & & & & & & \\
\hline 11 & 20 & .50 & & & & & & & & \\
\hline 12 & 20 & .25 & & & & & & & & \\
\hline 13 & 100 & 1 & & & & & & & & \\
\hline \multirow[t]{2}{*}{14} & 100 & $.25(213)$ & & & & & & & & \\
\hline & 20 & $.50(455)$ & & & & & & & & \\
\hline \multirow[t]{2}{*}{15} & 60 & 1 (213) & & & & & & & & \\
\hline & 100 & $.25(455)$ & & & & & & & & \\
\hline
\end{tabular}

*Locus of noncontingent reinforcement

**Probability of noncontingent reinforcement

tOrder of presentation

tingent reinforcement was added to the baseline schedule at various temporal locations (timed from the beginning of the time period). A probability generator was sampled at the specified locus in each interval. The temporal location and $p$ of noncontingent reinforcement were varied across sessions. Thus, a bird would be contingeptly reinforced for the first response in a time period, and at some fixed point in an interval a bird would receive noncontingent reinforcement according to the specified p. Table 1 presents the experimental conditions and their order of presentation. Subjects were run 10 sessions at each condition, with two exceptions: the first baseline determination was 20 sessions for all subjects; birds 213 and 455 were run at Condition 14 for 15 sessions. Birds 213 and 455 were exposed to all loci and ps of noncontingent reinforcement. Birds 100, 218, 404 , and 50 were exposed to the range of ps of noncontingent reinforcement but only at one temporal location each. The ps of noncontingent reinforcement were presented in different sequences for these subjects to assess whether order effects contributed to the functions obtained. All experimental sessions were terminated after 25 time periods had been presented.

\section{RESULTS}

Table 2 presents running response rates (total responses divided by session time after reinforcement and postreinforcement times had been subtracted) for individual subjects. Running rates were used to eliminate response rate variation resulting from changes in the pause time between a reinforcement and the next response. Investigation of postreinforcement pause data showed some changes as a function of the locus and $p$ of $\mathrm{S}_{\mathrm{NC}}^{\mathrm{R}}$ (see Figure 2). The data in Table 2 represent means of the last five sessions at a condition. The $p=0$ condition (baseline) was determined three times for birds 213 and 455 . The means of these three determinations were used for the $p=0$ conditions at each temporal placement. Table 2 shows that as the $\mathrm{p}$ of $\mathrm{S}_{\mathrm{NC}}^{\mathrm{R}}$ was increased, there was some tendency for response rates to decrease in several birds. However, some birds did not show this relationship. For example, bird 455 showed rate increases with increases in $\mathrm{S}_{\mathrm{NC}}^{\mathrm{R}}$ when $\mathrm{S}_{\mathrm{NC}}^{\mathrm{R}}$ was presented at 100 sec; bird 50 did not show much change at any of the $\mathrm{S}_{\mathrm{NC}}^{\mathrm{R}}$ ps when $\mathrm{S}_{\mathrm{NC}}^{\mathrm{R}}$ was delivered at $20 \mathrm{sec}$; when $\mathrm{S}_{\mathrm{NC}}^{\mathrm{R}}$ was presented at $60 \mathrm{sec}$, bird 404's lowest rate was obtained at the $\mathrm{p}=0$ condition. The recovery conditions are shown in parentheses in Table 2. In general, the original determinations were closely replicated.

As shown in Table 2, comparison of response rates at the three $S_{\mathrm{NC}}^{\mathrm{R}}$ loci revealed no systematic differences as a function of the probability of $S_{N C}^{R}$ (also see Figure 1).

Based on two criteria, the data in Table 2 represent "steady state" responding: (1) the standard deviations of individual subject mean response rates fell within a range of .14 and .03 , with a median of approximately .06 ; (2) the subjects exposed to Condition 14 (see Table 1) re-

Table 2

Running Response Rates (Responses/Second) at Each Experimental Condition

\begin{tabular}{rcccc}
\hline Subject & $\mathrm{p}^{*}=1$ & $\mathrm{p}=.50$ & $\mathrm{p}=.25$ & $\begin{array}{c}\mathrm{p}=0 \\
\text { (Baseline) }\end{array}$ \\
\hline \multicolumn{5}{c}{ Noncontingent Reinforcement at $100 \mathrm{Sec}$} \\
455 & $.93(.90)$ & .83 & $.71(.75)$ & .83 \\
213 & $.45(.60)$ & .50 & $.59(.56)$ & .81 \\
100 & .49 & .49 & .64 & .64 \\
218 & 1.74 & 1.29 & 1.89 & 1.92 \\
\multicolumn{5}{c}{ Noncontingent Reinforcement at $60 \mathrm{Sec}$} \\
455 & .78 & .97 & .94 & .83 \\
213 & $.90(.94)$ & .67 & .64 & .81 \\
404 & .73 & .96 & .69 & .46 \\
455 & .86 & $.88(.93)$ & .97 & .83 \\
213 & .53 & .52 & .63 & .81 \\
50 & .71 & .71 & .79 & .75 \\
\hline
\end{tabular}

*Probability of noncontingent reinforcement 


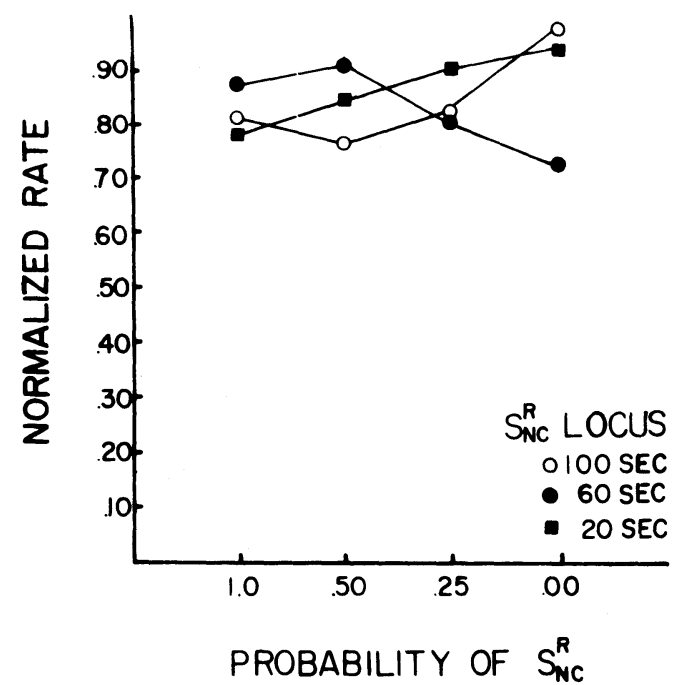

Figure 1. Group normalized response rates at each probability and temporal locus condition.

vealed no systematic change in rate between Days 6 and 10 and 11 and 15.

Birds $100,218,404$, and 50 were exposed to the ps of $S_{\mathbf{N C}}^{\mathbf{R}}$ in different orders of presentation at a particular locus. Table 2 shows that this procedural variation in presentation order did not produce systematic differences between birds successively exposed to increasing ps of $S_{N C}^{R}$ and birds presented with $S_{N}^{R}$ ps in different orders.

Figure 1 presents group means at each $S_{N C}^{R}$ locus. The data points are normalized response rates; that is, the rate at each $S_{N C}^{R} p$ is expressed as a fraction of the highest rate at the prevailing $S_{N}^{R}$ locus. For each locus, the normalized values of individual subjects were averaged for each of the different $S_{\mathrm{NC}}^{\mathrm{R}}$ ps. The data for the $S_{\mathrm{NC}}^{\mathrm{R}}$ at the 100 -sec condition revealed an average $.16 \%$ decrease at the $p=1$ condition when compared to the $\mathrm{p}=0$ condition. Relative to the $\mathrm{p}=0$ condition, the average rate at the $p=1$ condition was . $15 \%$ higher when $\mathrm{S}_{\mathrm{NC}}^{\mathrm{R}}$ was preserited at $60 \mathrm{sec}$, and it was $.15 \%$ lower when $S_{\mathbf{N}}^{\mathbf{R}}$ was delivered at $20 \mathrm{sec}$. The trends shown in the 100- and 20-sec conditions are representative of the data for several individual subjects exposed to these conditions. The data from bird 404 were responsible for the low average rate at the $p=0$ condition when $\mathrm{S}_{\mathrm{NC}}^{\mathrm{R}}$ was presented at $60 \mathrm{sec}$.

The time from presentation of a reinforcer to the next response, the postreinforcement pause $\left(\mathrm{PS}^{\mathrm{R}} \mathrm{P}\right)$, was averaged over the last five sessions at each $p$ and temporal locus combination. Figure 2 shows separate mean values for pauses after $S_{C}^{R}\left(P_{C}^{R} P\right)$ and $S_{N C}^{R}\left(P_{N C}^{R} P\right)$. Data are not provided for baseline determinations. Intruding $S_{\mathrm{NC}}^{R}$ at $20 \mathrm{sec}$ produced longer pause times after $S_{N C}^{R}$ relative to $S_{C}^{R}$ pauses. Conversely, presenting $S_{N C}^{R}$ at $100 \mathrm{sec}$ resulted in longer pauses after $S_{C}^{R}$ relative to $S_{N C}^{R}$ pauses. Bird 218 did not consistently show this effect at the 100 -sec condition. The $\mathbf{P S}^{\mathbf{R}} \mathbf{P}$ data at the 60-sec temporal locus were not as consistent across pigeons as the results at the other temporal loci. At the $p=1$ value, $P^{R}$ Ps for the 60 -sec locus were indistinguishable for all birds. A similar effect was obtained at the $p=.5$ value for birds 213 and 404, while bird 455 showed a somewhat longer $P^{R} P$ after $S_{C}^{R}$. At the $p=.25$ value, birds 455 and 213 showed a longer $\mathrm{PS}^{\mathrm{R}} \mathrm{P}$ after $\mathrm{S}_{\mathbf{C}}^{\mathrm{R}}$, while bird 404 's $\mathrm{PS}^{\mathrm{R}} \mathrm{Ps}$ were indistinguishable.

The mean number of $S_{N C}^{R}$ s actually presented at a particular $p$ of $S_{N}^{R}$ c was always within three whole numbers of the nominal values. Thus, when the $p$ of $S_{N C}^{R}$ was increased by some value, the actual frequency of $S_{N}^{R} C$ increased accordingly.

\section{DISCUSSION}

Cole (1973), Lattal (1974) and Rachlin and Baum (1972) found that as the rate or amount of $S$ RC was increased relative to the rate or amount of $S_{C}^{R}$, response rates decreased. This finding was consistent across all pigeons studied in the three experiments. In the present study, some subjects showed rate decreases with increases in SRc frequency. For other subjects,

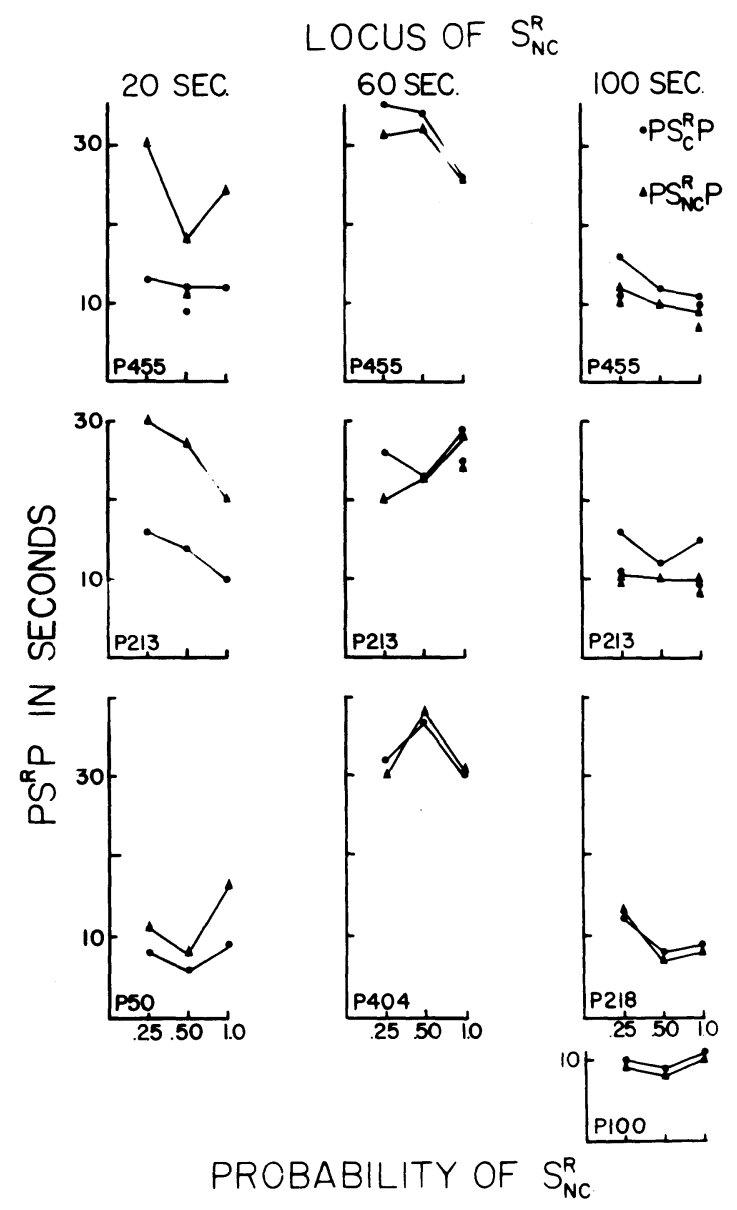

Figure 2. Mean postreinforcement pauses after contingent $\left(P_{C}^{R} \mathbf{P}\right)$ and noncontingent $\left(P_{C}^{R} \mathbf{P}\right)$ reinforcerers for individual subjects. Data presented for each probability and temporal locus condition. 
rates did not show much change at a particular $S_{N C}^{R}$ locus with changes in the frequency of $S_{N C}^{R}$. Lastly, two birds (404 and 213 ) had higher rates of responding at the $p=1$ condition than at the $p=0$ condition. One reason for the lack of uniform agreement between the present data and those of Cole and Rachlin and Baum might be that a different type of concurrent schedule was used in the present study. The temporal relations between $S_{C}^{R}$ and $S_{N C}^{R}$ were relatively constant in the present study. Birds received $S_{C}^{R}$ for the first response in an interval and $\mathrm{S}_{\mathrm{NC}}^{\mathrm{R}}$ (according to the p parameter) at a specific temporal locus within the interval. Since subjects almost always obtained $S_{C}^{R}$ within $1 \frac{1}{2} \mathrm{sec}$ of its availability, there were no dramatic variations from the nominal $S_{N}^{R}$ temporal specification. Although subjects could receive $S_{C}^{R}$ successively when the $p$ of $S_{N C}^{R}$ was less than one, $S_{N C}^{R}$, when presented, always followed $S_{C}^{R}$. In the Cole and Rachlin and Baum studies, $S_{C}^{R}$ and $S_{N C}^{R}$ were programmed such that the number of successive $S_{C}^{R}$ and $S_{N C}^{R}$ pairings and the temporal relations between $S_{C}^{R}$ and $S_{N C}^{R}$ were not systematic. Exactly what aspects of the present procedure were responsible for some birds showing increases and others showing decreases in response rate with increases in $S_{N C}^{R}$ is not clear. Perhaps the temporal regularities between reinforcers produced close unprogrammed pairings of responses and $\mathrm{S}_{\mathrm{NC}}^{\mathrm{R}}$ more frequently with some subjects than with others.

Previous experiments studied conditions in which the percentage of the subjects' total reinforcement in a session from a noncontingent source ranged between $0 \%$ and $100 \%$. In the present study, $50 \%$ at most, of the total reinforcements were from a noncontingent source. In order to make more complete comparisons between Cole's, Lattal's and Rachlin and Baum's procedures and the present one, more variation in the amount of $\mathrm{S}_{\mathrm{NC}}^{\mathrm{R}}$ received by the pigeons is required. Since, using the present procedure. it is possible only to program $50 \%$ of the reinforcement in a session from a noncontingent source (i.e., the $p=1$ condition), some other manipulation besides probability must be used. One possibility is magnitude of reinforcement.
It is interesting that some birds showed increases in response rate with increases in $\mathrm{S} \mathrm{R}_{\mathrm{C}}$ frequency. If the pigeons discriminate (as measured by differential response rates) between contingent and noncontingent reinforcement solely on the basis of dependency between responses and reinforcers, the present procedure should have been ideal for this discrimination. In the $p=1$ condition, pigeons received $S_{N C}^{R}$ once each interval following $S_{C}^{R}$ by some relatively constant delay. In addition to dependency cues, then, there was the cue that a contingent reinforcement was always followed by a noncontingent reinforcement. As the data illustrate, those two sources of cues did not always produce decreases in rate. The control exerted by certain schedules may be such that discrimination based on dependency does not occur.

Relative to the response rate measure, the $P^{R^{R}} \mathbf{P}$ data were more consistent across subjects at the different temporal loci of $S$ RC, except when $S_{N C}^{R}$ was presented at $60 \sec (p=.25)$. The differences between $\mathrm{PS}_{\mathrm{C}}^{\mathrm{K}} \mathrm{P}$ and $\mathrm{PS} \mathrm{NC}_{\mathrm{C}}^{\mathrm{R}} \mathrm{P}$ durations demonstrate the importance of temporal locus of $S_{N C}^{R}$. When the interval following $S_{N C}^{R}$ was longer than the interval following $S_{C}^{R}$, PS R P Ps were longer, and vice versa.

\section{REFERENCES}

Cole. B. K. Schedules of concurrently contingent and noncontingent reinforcement. In F. J. McGuigan and D. B. Lumsden (Eds.). Contemporany approaches to conditioning and learning. New York: Wiley, 1973. Pp. 167-172.

LatTal. K. A. Combinations of response-reinforcer dependence and independence. Joumal of the Experimental Analysis of Behavior. 1974, 22. 357-362.

RAChlin, H., \& BAUM. W. M. Effects of alternative reinforcement: Does the source matter? Journal of the Experimental A nalysis of Behavior, 1972, 18. 231-241.

(Received for publication December 22. 1975.) 